\title{
TRAJETÓRIA DO ENSINO MÉDIO E DA EDUCAÇÃO PROFISSIONAL NO BRASIL
}

\author{
E. R. S. LIMA ${ }^{1}$, F. N. SILVA ${ }^{2}$, L. L. S. SILVA ${ }^{3}$ \\ ${ }^{1}$ Universidade do Estado do Rio Grande do Norte, ${ }^{2}$ Universidade Federal do Rio Grande do Norte, ${ }^{3}$ Instituto \\ Federal do Rio Grande de Norte \\ natalia_silva_18@hotmail.com ${ }^{1}$
}

Submetido 09/03/2017 - Aceito 27/08/2017

DOI: $10.15628 /$ holos.2017.5753

\section{RESUMO}

Nesse artigo, delineia-se o percurso histórico do Ensino Médio e da Educação Profissional no Brasil. Buscou-se conhecer como o Ensino Médio e a Educação Profissional foram institucionalizados no Brasil a partir da seguinte questão: Como o Ensino Médio e a Educação Profissional vêm se constituindo ao longo da história da educação brasileira? Para responder ao questionamento realizou-se uma pesquisa de natureza qualitativa na qual foi dado enfoque histórico, partindo-se de análise documental e bibliográfica. Considerou-se ainda, aspectos vinculados à Educação Profissional em suas interações e influências socioculturais e econômicas, tais como: a relação trabalho, educação e sociedade e a divisão social do trabalho. A partir do que foi pesquisado percebeu-se, com ênfase na trajetória da Educação Profissional e do Ensino Médio, mudanças que foram efetivadas dentro de um processo histórico diversificado que acompanha um

conjunto de aspectos sociais, econômicos, políticos e educacionais em âmbito nacional e internacional em um mundo globalizado. Diante do que foi discutido ao longo do texto, defende-se uma Educação Profissional de forma integrada à Educação Básica. Um tipo de ensino que permita a integração do ensino científico, produzido e acumulado historicamente, com a formação profissional. Dessa forma, quem sabe? Exista uma educação que interesse à classe trabalhadora; uma formação que não seja apenas técnica, mas que garanta uma formação humana integral. Para tanto, torna-se inevitável às políticas e reformas educacionais, mas que estas tentem ultrapassar as barreiras que impedem uma educação científica e tecnológica integrada culturalmente ao momento histórico vivenciado no século XXI.

PALAVRAS-CHAVE: História da Educação, Ensino Médio, Educação Profissional.

\section{TRAJECTORY OF MIDDLE SCHOOL AND PROFESSIONAL EDUCATION IN BRAZIL}

\begin{abstract}
In this article, we outline the historical course of Secondary Education and Professional Education in Brazil. It was sought to know how the Secondary Education and Professional Education were institutionalized in Brazil from the following question: How have the Secondary Education and Vocational Education have been constituted throughout the history of Brazilian education? In order to respond to the questioning, a qualitative research was carried out in which a historical approach was taken, starting with documentary and bibliographical analysis. It was also considered aspects related to Professional Education in their socio-cultural and economic interactions and influences, such as: the relation work, education and society and the social division of labor. Based on what was researched, it was noticed, with emphasis on the trajectory of Professional Education and High School, changes that were carried out within a diversified
\end{abstract}

historical process that accompanies a set of social, economic, political and educational aspects in national and international scope In a globalized world. In view of what was discussed throughout the text, professional education is defended in an integrated way to Basic Education. A type of education that allows the integration of scientific education, produced and accumulated historically, with vocational training. That way, who knows? There is an education that interests the working class; A training that is not only technical, but which guarantees an integral human formation. To that end, it becomes inevitable for educational policies and reforms, but for them to try to overcome the barriers that prevent culturally integrated scientific and technological education from the historical moment of the twenty-first century.

KEYWORDS: History of Education, Secondary Education, Professional Education. 


\section{INTRODUÇÃO}

Ao longo da história da educação brasileira à educação do povo, dos trabalhadores eram destinados programas e atividades extra-escolares, com destaque para as iniciativas e organizações não estritamente educativas. Existia uma preocupação em formar mão-de-obra para o trabalho, que detivesse saberes profissionais específicos para atender às demandas que emergiam no contexto social e econômico.

Nesse artigo, delineamos o percurso histórico do Ensino Médio e da Educação Profissional no Brasil, para conhecermos como foram institucionalizados no cenário brasileiro a partir da seguinte questão: Como o Ensino Médio e a Educação Profissional vem se constituindo ao longo da história da educação brasileira?

Diante disso, houve a necessidade de trazer para o texto a história do Brasil, com foco nas relações estabelecidas entre trabalho e educação nas reformas e reformismos das políticas educacionais, ocorridas no contexto de globalização do Século XVI até a primeira década do Século XXI.

A globalização e seus variados modos de configuração tiveram origem com a formação dos primeiros estados europeus e com a expansão marítima europeia no Século XV, quando Espanha e Portugal lançam-se ao mundo em busca de novas possibilidades de mercado para englobar a economia.

Portugal foi o primeiro Estado-nação a promover a expansão marítima, por possuir características fundamentais para isso, destacando-se: a Revolução de Avis, que promoveu o centralismo político; a localização geográfica (por meio da conquista de Ceuta, quando passa a controlar o fluxo do comércio), a pesca, e a criação da Escola de Sagres (desenvolvimento das técnicas navais). (BOXES, 2000). Assim, a partir do movimento de expansão marítima e do Tratado de Tordesilhas, Portugal chega ao Brasil em 1500, conquistando a nossa terra como Colônia.

Para uma organização lógica e didática do texto sua estruturação apresenta-se da seguinte maneira: No tópico 2 apresentamos o Ensino Médio e a Educação Profissional da Colônia ao Império Brasileiro; no tópico 3 apresentamos o Ensino Médio e a Educação Profissional no Brasil República: período de reformas e reformismos e por último nossas considerações acerca da constituição do Ensino Médio e da Educação Profissional no Brasil.

\section{ENSINO MÉdIO E EDUCAÇÃO PROFISSIONAL DA COLÔNIA AO IMPÉRIO BRASILEIRO}

Do Período Colonial até o início do Império no Brasil - o trabalho na sociedade brasileira é marcado pelo escravismo e desvalorização do trabalho manual. Isso combinava, literalmente, com a economia portuguesa que se baseava no pacto colonial, fundamentado na relação metrópole-colônia (colonialismo). Assim, o Brasil passou a fornecer matéria-prima, necessitando, para isso, de mão-de-obra para o trabalho na agricultura. Por essa razão, os negros trazidos da 
África, e os índios foram escravizados para compor a força de trabalho, necessária ao desenvolvimento capitalista desse momento.

O trabalho manual, sendo predominantemente realizado pelos negros, não tinha prestígio social e o trabalho escravo foi a forma que os portugueses encontraram de aumentar a produção da economia colonial, sem precisar pagar pelo trabalho. Por isso, é que as elites colonial e imperial temiam a abolição da escravidão, pois sabiam que, com o fracasso desse tipo de trabalho, ocorreriam perdas financeiras.

O trabalho, no Brasil-Colônia, esteve, também, relacionado ao que foi chamado de "artes e ofícios", destinando-se à Educação Profissional de aprendizes para o artesanato, a manufatura e a indústria. A educação artesanal acontecia de forma assistemática, a partir da troca de experiências entre os jovens e seus mestres. Já a educação industrial era desenvolvida através de processos sistematizados e regulamentados, em lugares especializados, e a educação manufatureira, uma combinação das produções anteriores, acontecia por processos, que, às vezes, eram formalizados em instituições escolares (CUNHA, 2000).

Para compreendermos melhor a trajetória da Educação Profissional vamos localizá-la na história da educação no Brasil que se inicia com a vinda dos jesuítas, em 1549. Os jesuítas, ao chegarem ao Brasil, sistematizaram uma organização educacional com fortes influencias do modelo europeu. Os padres criaram conventos e escolas, estendendo-os para o interior da Colônia e para as aldeias já existentes. Essa fase da educação jesuítica, de acordo com Saviani (2008), foi marcada pelo plano criado por Manuel da Nóbrega. O plano propõe Educação Profissional, de forma a tornar a educação dual, pois era ofertada de um lado a Educação Profissional e de outro educação propedêutica.

A educação colonial no Brasil foi organizada em três fases. Na primeira fase, no "período heróico", a escola elementar tinha o objetivo de alfabetizar e de catequizar, em busca de uma unidade espiritual entre os índios e os filhos dos colonos brancos. Já na segunda fase, a escola, decorrente da filosofia da educação jesuítica de Portugal, destinava o ensino elementar à elite colonial (SAVIANI, 2007). Esse ensino acontecia por meio de cursos, oferecidos na família e nos colégios. Os cursos foram regularizados pelo RatioStudiorun um documento que apresentava o conteúdo e a metodologia a serem utilizados pelos professores.

No século XVIII, com as influências das ideias iluministas, várias reformas políticas e administrativas se instituíram em Portugal, e em todas as suas Colônias. Uma dessas reformas mudou o rumo da educação no Brasil. Em 1759, uma lei determina a expulsão dos jesuítas, pelo Marques de Pombal, que decidiu que os jesuítas não participariam mais da vida da metrópole e das colônias. Com isso, foi instaurada a Reforma Pombalina (1759-1822) na educação, para substituir o sistema de ensino da Companhia de Jesus.

Nesse período da Reforma Pombalina, o ensino sofreu modificações. Deixa de ter caráter somente religioso, e passa a ser útil aos interesses do Estado, portanto, a educação torna-se laica. No âmbito dessa discussão, Cunha (1986) afirma que as políticas pombalinas recaíam na necessidade de Portugal intensificar a produção para o comércio. Nesse sentido, era fundamental libertar os índios dos padres e torná-los integrados à economia, como mão de obra escrava, pois os índios eram protegidos pelos jesuítas. 
Com isso, o modelo educacional jesuítico foi substituído pela organização de aulas régias. De acordo com Queiroz (2010), as aulas régias eram ministradas por professores que possuíam cargos vitalícios e reproduziam os antigos métodos utilizados pelos jesuítas, devido ao fato de terem sido formados nesse modelo educacional.

No sistema de aulas régias, o ensino elementar estava organizado em ensino, da leitura e escrita para que o aluno, posteriormente, estudasse as diversas matérias (latim, gramática, grego, retórica...). Essas podem ser equiparadas ao ensino secundário ou ao curso de humanidades dos jesuítas, e ainda, ao que hoje nós temos como Ensino Médio propedêutico. Depois, desse ensino o aluno estava preparado para prosseguir na Universidade de Coimbra ou em outros centros europeus.

Na Colônia, as grandes fazendas foram centros de produção e de consumo, havendo rudimentares oficinas. Durante esse período, a Educação Profissional ocorria pela aprendizagem de ofícios artesanais e manufatureiros, sendo desenvolvida em colégios, fazendas, engenhos e nas residências dos jesuítas. Vimos assim, que houve a necessidade da aprendizagem de ofícios, principalmente quando os senhores instalaram engenhos de açúcar nas fazendas e introduziram as máquinas moedeiras de cana-de-açúcar. Cunha (2000) ressalta que as Corporações de Ofícios desempenhavam dupla função de controle monopolista. Primeiro, proibiam aos trabalhadores que não tinham vínculo de praticar atividades artesanais; segundo, controlavam as relações inter/ofícios.

Com a mudança da sede do Reino Português para a Colônia, em 1808, iniciaram-se as primeiras instituições formadoras de artífices. Mas, segundo Cunha (2000), entre as instituições de aprendizagem manufatureiras, encontra-se a Casa Pia da Bahia, onde o ensino de ofícios manufatureiros aos órfãos iniciou-se bem cedo, em 1799.

Em 1809, o ensino e aprendizagem de ofícios para o trabalho passam a acontecer dentro dos estabelecimentos industriais, as chamadas Escolas de Fábrica, que servem de referência histórica para as unidades de Educação Profissional. No entanto, o ensino de ofícios, também, foi desenvolvido na Imprensa Régia.

Na Colônia brasileira, o desenvolvimento econômico era fundamentado na exploração de matéria-prima, e não havia a exigência de trabalhadores qualificados, portanto, não houve a preocupação em ofertar educação para a classe trabalhadora. A Educação Profissional, nesse período, teve objetivo assistencialista, e só se inicia, predominantemente, no século XIX, quando surgiram as Escolas de Fábricas.

A chegada da Família Real ao Brasil causou várias mudanças na Colônia. Primeiro, o Brasil superou a condição de Colônia e, a partir da abertura dos portos, começou a comercializar com outras metrópoles. Houve a liberação das manufaturas, por Dom João, visto que tinham sido proibidas as manufaturas por sua mãe, D. Maria I, em 1785 (BOXES, 2000). Com bases nesses acontecimentos, Portugal enfraqueceu-se diante da política econômica europeia e no cenário internacional, levando a independência do Brasil, em 1822, pela elite brasileira. Com isso, iniciase o período do Brasil - Império (1822 - 1889).

No contexto do Brasil-Império, conforme Moura (2012), foram criadas instituições de ensino e ofícios manufatureiros, tanto pela sociedade civil, como instituições criadas pelo próprio Estado em Estabelecimentos Militares, Entidades Filantrópicas, Asilo de Meninos Desvalidos, 
Liceus de Artes e Ofícios, e a Escola Industrial os quais serão situados em seus espaços históricos, econômicos e sociais. No Brasil Império, fica estabelecido pelo Decreto no 1.331 - A/ 17/02/1854, que a instrução primária ficaria organizada em duas classes: a elementar e a superior. Para a classe elementar, o ensino volta-se para a religião, leitura e escrita, noções de gramática e aritmética. Para a classe superior, o ensino seria de desenvolvimento da aritmética em suas aplicações práticas, história sagrada, elementos da história e geografia, geometria elementar, noções de música e outras disciplinas (SANTOS, 2010, p. 06).

Nesse contexto foram construídos os primeiros liceus, entre os quais, o Ateneu do Rio Grande do Norte, em 1835, o Liceu da Bahia e o Liceu da Paraíba, em 1836. Foram criados outros liceus, mas não obtiveram êxito. De acordo com Santos (2010), os liceus tinham como objetivo fornecer aos seus discentes conhecimentos básicos para a admissão no ensino superior até a metade do século XX. Desse modo, o que temos hoje como Ensino Médio, ficou restrito a estabelecimentos como os liceus no Brasil Império em forma de cursos livres.

Assim sendo, em 1837 foi criado, no Rio de Janeiro, o Colégio D. Pedro II, antigo Seminário de São Joaquim. O Colégio $D$. Pedro II era frequentado pela elite dirigente e ofertava cursos com duração de 6 a 8 anos, com estrutura escolar orgânica e seriada. Pelo Decreto no 1.331/1854, Couto Ferraz ${ }^{1}$ tentou ampliar a função dos estudos secundários, colocando-os na base de especializações técnicas. O curso do Colégio D. Pedro II ficaria dividido em estudos de $1 \underline{a}$ e 2a classes.

Já nos Estabelecimentos Militares, o ensino de ofícios manufatureiros se desenvolveu a partir do aparato administrativo, judiciário, fiscal e militar. Esses estabelecimentos "[...] foram, assim, os primeiros a explicitarem, a utilização no Brasil [...] de menores órfãos, pobres ou desvalidos, como matéria-prima humana para a formação sistemática da força de trabalho para seus arsenais [...]." (CUNHA, 2005, p. 112).

Os momentos e movimentos históricos do Ensino Secundário e da Educação Profissional no Brasil, até agora discutidos, inserem-se no segundo período de globalização, conforme lanni (1998) quando, insistimos em dizer que o capitalismo se tornou transnacional, assumido como nacional, e expandiu o mercado e as forças produtivas, em busca de matérias-primas.

\section{BRASIL REPÚBLICA: PERÍODO DE REFORMAS E REFORMISMOS NO ENSINO MÉDIO E NA EDUCAÇÃO PROFISSIONAL}

Na República, o Brasil adota o modelo político americano baseado no sistema presidencialista, quando, em 1889, é proclamada a república no país, pelo Marechal Deodoro. Esse período não está acabado, mas ainda está sendo construído historicamente, já que vivemos sob o modelo de República Federativa presidencialista, no início do século XXI.

Na conjuntura de construção do Estado Republicano Nacional houve várias reformas na organização da educação brasileira. Essas reformas nacionais apontam para ideias prevalecentes do poder central. Ou seja, a classe dominante continuou "pensando" a educação do País. Por essa razão, algumas dessas reformas são apenas reformismos, pois permaneceram dentro da

\footnotetext{
${ }^{1}$ Luís Pedreira do Couto Ferraz, primeiro e único Visconde do Bom Retiro- RJ. Foi um advogado e político brasileiro. Foi deputado geral, presidente da província do Rio de Janeiro, conselheiro de Estado e senador do Império do Brasil de 1867 a 1886 .
} 
mesma ideologia de elaboração política, ou seja, aquela que respalda os interesses econômicos do capital sobre a educação em um mundo globalizado em suas dimensões sociais e culturais como vimos na seção anterior.

O primeiro período da República (1889 - 1930) é marcado por grandes acontecimentos. Nesse período, a educação foi planejada pelos positivistas brasileiros, que também efetivaram as Reformas políticas, visto que, de acordo com Severino (1986, p. 15): "a República nasceu sob a influência e inspiração do positivismo que marca, sobretudo, sua visão educacional." Consideramos importante reafirmar que as reformas iniciaram-se em 1890, com a Reforma de Benjamim Constant (Ministro da Instrução, Correios e Telégrafos) que introduziu de maneira profunda, as ideias de positivismo ${ }^{2}$ de Augusto Comte no Brasil.

Nessa mesma reforma, por meio do Decreto no. 981, de 8 de novembro de 1891, se buscou a gratuidade da escola primária, que já havia sido estabelecida pela Constituição Brasileira (1891). Essa Reforma, também, teve como objetivo, segundo Santos (2010), proporcionar aos jovens brasileiros as condições básicas para a matrícula nos cursos superiores, visto que Benjamin Constant instituiu a obrigatoriedade de se realizar exames de madureza para receber um certificado correspondente à conclusão do curso secundário, para, assim, poder ingressar no Ensino Superior.

Em 1891, houve um crescimento no número de fábricas no Rio de Janeiro, à época capital do Brasil. Com isso, por meio do Decreto № 1.313/1891, providências foram tomadas para regularizar o trabalho infantil nas fábricas. O referido Decreto veio, portanto, a proibir o trabalho de crianças menores de 12 anos nas fábricas.

Em 1901, por meio do Decreto n.o 3.890, de 1ㅇ de janeiro de 1901, foi aprovado o Código dos Institutos Oficiais de Ensino Superior e Secundário, dependentes do Ministério da Justiça e Negócios Interiores. A educação brasileira passa a ser norteada pelo Código Epitácio Pessoa, assim denominado o Código supracitado. Houve, a partir daí, preocupação com aspectos regulamentares, sendo baixadas normas para as escolas particulares e para o processamento dos exames de madureza. Essas escolas organizavam horários, programas, exames e salários de professores. Todavia, vemos que o início do século XX inovou a história da Educação Profissional do país, posto que, de acordo Tavares (2005, p. 23) “[...] houve um esforço público de organização da formação profissional, modificando a preocupação nitidamente assistencialista de atendimento a menores abandonados e órfãos, para a da preparação de operários para o exercício profissional".

Em 1906, o ensino profissional passou a pertencer ao Ministério da Agricultura, Indústria e Comércio, "mediante a busca da consolidação de uma política de incentivo para preparação de ofícios dentro destes três ramos da Educação econômica." (TAVARES, 2005, p. 23). Já no ano de 1909, Nilo Peçanha cria as Escolas de Aprendizes Artífices, destinadas aos pobres. Essas escolas assemelhavam-se aos Liceus de Artes e Ofícios eram destinados ao ensino industrial. (TAVARES, 2005).

\footnotetext{
${ }^{2}$ As ideias baseadas na corrente sociológica do positivismo abandonam a consideração das causas e dos fenômenos, tendo a ciência como a investigação do real. Na escola de inspiração positivista os estudos científicos prevalecem sobre os literários. É importante formar os alunos sob a ordem, ensinando a obediência e a hierarquia. A máxima "ordem e progresso" na bandeira brasileira é reflexo da influência do positivismo na política nacional. (GERMANO, 2005).
} 
Em 1911, houve a Reforma Rivadávia Correa, por meio do Decreto no 8.666/1911, que objetivava que o curso secundário não fosse, apenas, um intermediário ao nível seguinte, mas também proporcionasse aos estudantes conhecimentos fundamentais e necessários para um bom desempenho dos deveres do cidadão na vida social. Após essa Reforma, o ensino secundário passou a ter duração de sete anos. Essa Reforma teve como foco o ensino secundário, já que sugeriu mudanças no currículo do Colégio D. Pedro II, que, em 1911, passou a ser chamado de Ginásio Nacional.

No ano de 1915, por meio do Decreto no 11.530/1915, houve a quarta reforma, a Reforma Carlos Maximiliano, para reorganizar o ensino, fazendo voltar o ensino secundário e superior à condição de estabelecimentos oficiais e equiparados. Foram instituídos os exames vestibulares, e o ensino secundário volta-se a preparar os jovens para realizar o vestibular. 0 ensino secundário passou a ter duração de cinco anos (SANTOS, 2010). Nessa época, consistia do Ginásio Nacional, mantido pelo Governo Federal no Rio de Janeiro e de um ginásio mantido em cada capital dos Estados, sob responsabilidade dos governos estaduais.

Na década de 1920, de acordo com Tavares (2005. p. 24), "foi criada uma comissão especial para fazer o Serviço de remodelagem do Ensino Profissional Técnico destinando esse tipo de educação tanto para ricos como para pobres [...]." Em 1924, no Liceu de Artes e Ofícios de São Paulo foi construída a Escola Profissional Mecânica, primeira iniciativa de ensino metódico de ofícios para as ferrovias. Em 1925, aconteceu a última reforma do ensino secundário na "República Velha". A reforma foi proposta pelo Ministro João Luís Alves, que buscou implementar o curso secundário seriado, de seis anos de duração, e com frequência obrigatória. O ministro procurava, com essa reforma, ressaltar o aspecto formativo do ensino secundário. No entanto, esse ensino continuou sendo visto como um mecanismo para o ensino superior e de ascensão social. (SANTOS, 2010).

Em 1927, o Decreto no. 5.241/1927 estabeleceu que o ensino profissional fosse obrigatório nas escolas primárias, no Colégio D. Pedro II e em outras instituições de educação semelhantes. As disciplinas curriculares compreendiam: desenho, trabalhos manuais ou rudimentos de artes e ofícios ou indústrias agrárias (BRASIL, 1927).

Vimos, até o momento, que as reformas, implantadas no Brasil para o Ensino Secundário e para a Educação Profissional, podem ser compreendidas como ações do Estado em uma perspectiva hegemônica. Trata-se de uma forma de localismo globalizado, no sentido ensejado por Boaventura Santos (2002), forjado por relações desiguais para escamotear os conflitos entre capital/trabalho e os sistemas de formação e qualificação da força de trabalho, necessária ao capital já globalizado, como discutimos na seção anterior. No ano de 1930, inicia - se um novo período republicano no Brasil quando - no contexto nacional - vários segmentos sociais (operários, universitários, artistas) estavam à margem da sociedade e começavam a se organizar para uma participação mais ativa na vida econômica, política e social do País.

Na conjuntura da "Nova República", há a expansão das novas forças produtivas, com a intensificação da divisão social e técnica do trabalho, ao mesmo tempo em que a maioria da população se encontrava mais pobre. Contudo, a educação continuava sendo vista como investimento e preparação para o mercado de trabalho (COELHO, 1990, p. 54). Nessa conjuntura, o ensino secundário continuou passando por reformas. Em 1931, com o governo de Getúlio Vargas, foi criado o Ministério da Educação e da Saúde, tendo, como ministro, Francisco Campos. 
Um ano depois, foi estabelecido o Decreto no 19.890/1932 que deu origem a Lei Orgânica do ensino secundário, a qual definia que o ensino secundário teria duração de sete anos, dividido em ginásio, com quatro anos de duração, e colegial, com três anos. (SANTOS, 2010).

Em 1932, aconteceu, no país, o Manifesto dos Pioneiros da Educação Nova, que "assumia a perspectiva de uma escola democrática e se propunha a proporcionar oportunidade para todos." (MOURA, 2012, p. 49). Esse Manifesto definia que a educação deveria ser estruturada em duas categorias: a primeira de atividades humanísticas e de ciência; a segunda de caráter técnico. O Manifesto representa o pensamento das elites da época sobre o modo de conduzir a sociedade pelos novos caminhos abertos pela industrialização, ocupando a educação, nesse processo, um papel primordial. De acordo com Kulesza (2002, p.18), o Manifesto anunciava a preparação técnica vinda por meio da escola secundária.

Em 1942, houve a Reforma Capanema por meio do Decreto № 4.244/1942, que estruturou a educação brasileira, coerente às necessidades da indústria nacional geradora da reforma do ensino, alternando, assim, a denominação de "ensino secundário" para Cursos Colegiais, divididos em dois ciclos: Clássico e Científico. Essa Reforma estabelecia como objetivos do ensino secundário formar a personalidade integral do adolescente, formação espiritual e formação patriótica e humanística.

Ainda na década de 1940, o ensino secundário foi motivo de preocupação para a oferta do ensino agrícola, comercial e industrial, apesar de as escolas técnicas já existirem desde 1909. Com isso, foi criado, em 1942, o Serviço Nacional de Aprendizagem Industrial (SENAI). Essa instituição foi destinada a organizar e administrar escolas de aprendizagem industrial em todo o país, oferecendo um ensino aligeirado. Ocorreu, também, a implantação do Serviço Nacional de Aprendizagem Comercial (SENAC), em 1946, durante o governo do General Eurico Gaspar Dutra.

No ano de 1946, com base nos princípios defendidos pela Escola Nova ${ }^{3}$, é colocada em questão a necessidade de uma Lei de Diretrizes e Bases da Educação para organizar e estruturar a educação brasileira. Com isso, em 1961 foi aprovada a primeira Lei de Diretrizes e Bases da Educação Brasileira (LDB), Lei no 4.024/1961. O projeto de lei foi discutido durante 13 anos, até a sua aprovação. A primeira LDB foi inspirada nos princípios liberais do período de democratização que vivia a sociedade da época. Portanto, a Lei envolvia todos os níveis e modalidades de educação, atribuindo plena equivalência aos cursos acadêmicos e profissionalizantes.

No que se refere ao ensino secundário, a LDB de 1961 traz, em seu Título, VII no art. 33 que: "a educação de grau médio, em prosseguimento à ministrada na escola primária, destina-se à formação de adolescente". No art. 34, coloca, no mesmo plano de igualdade, o curso secundário, os cursos técnicos e os pedagógicos.

Com o golpe militar em 1964, as leis para a educação precisavam estar em sintonia com o novo modelo internacional de dominação, fazendo a caminhada do liberalismo para o autoritarismo do período. (AMADOR, 2002, p. 19). Nesse período de Ditadura Militar (1964 1985), de acordo com Germano (2005) apesar das reformas, o Estado se descomprometeu, gradativamente, em financiar a educação pública; os recursos foram comprometidos com o

\footnotetext{
${ }^{3}$ Escola Nova é um movimento de renovação do ensino que teve seu início no Brasil durante a década de 1920. Ele teve como uma de suas metas: eliminar o ensino tradicional que mantinha fins puramente individualistas, pois buscava princípios da ação, solidariedade e cooperação social. (KUELESZA, 2015).
} 
capital privado, repassando as verbas para as escolas particulares a exemplo do Sistema S. A iniciativa privada dominou a pré-escola, avançou no $2 \stackrel{\circ}{\circ}$ Grau e predominou no nível superior.

Seis anos após o início do Regime Militar no Brasil, foi aprovada a Lei no 5.692/1971 que vai regulamentar a política de educação para a prática. Essa Lei fixou as Diretrizes e Bases para o ensino de 1ㅇ e 2ㅇ Graus, esse último equivalente ao que temos hoje como Ensino Médio. Para Amador (2002, p. 20), a Lei no 5.692/1971 concomitante à Lei no 5.540/1968, que trata do ensino superior, "estavam a serviço do novo modelo político-econômico imposto ao país, onde a educação deveria atender às novas demandas do mercado capitalista, ou seja, o tecnicismo tomou conta da educação brasileira".

A Lei de 1971, em seu art. 1ㅇ, estabelece, como objetivo geral do 20 Grau, esta dupla função: preparar para uma profissão técnica e prosseguir os estudos. Assim, essa Lei propõe uma formação geral, na tentativa de formar sujeitos tanto para viver em sociedade, como para atender às exigências do mercado de trabalho, visto que a educação tinha uma concepção tecnicista e seguia a lógica da Teoria do Capital Humano ${ }^{4}$ uma das bases de sustentação racional do capitalismo globalizado.

Com a abertura política, em 1988, foi promulgada a nova Constituição Federal. Nessa Constituição, está estabelecido, no art. 205, que a educação deve preparar tanto para o exercício da cidadania, quanto para a qualificação para o trabalho. Explicita ainda, no art. 208, II, "a progressiva universalização do ensino médio gratuito" (BRASIL, CONSTITUIÇÃO FEDERAL, 1988).

A próxima reforma na educação veio acontecer, em 1996, quando era Presidente do Brasil era Fernando Henrique Cardoso, o FHC. O governo de FHC esteve voltado para políticas neoliberais para a educação, o que consistiu em políticas de recuo da participação estatal nas atividades econômicas e em poucos investimentos nas escolas públicas. Durante esse governo, foram elaborados vários documentos legais para orientação e funcionamento da educação brasileira. Foi elaborada e promulgada a nova Lei de Diretrizes e Bases da Educação no 9.394/1996. Além disso, foram criadas as Diretrizes Curriculares Nacionais para o Ensino Médio (DCNEM), os Parâmetros Curriculares Nacionais do Ensino Médio (PCNEM) e o Decreto no $2.208 / 1997$, os quais representaram o grande marco normativo dessa reforma.

A LDB vigente detalha os encaminhamentos para a implementação das reformas educacionais, explicita as linhas gerais e as metas ensejadas pela Constituição Federal de 1988. A referida Lei reorganiza toda a educação brasileira em dois níveis: Educação Básica (Educação Infantil, Ensino Fundamental e Ensino Médio) e Educação Superior. No Inciso I, do art. 21, da LDB é determinado o Ensino Médio como "a última etapa da educação básica." (BRASIL, LDB, 1996).

É possível observarmos, na referida Lei, as diferentes possibilidades de ofertas permitidas ao Ensino Médio, pois, além de garantir a formação geral, preceitua assegurar a formação profissional, apresentando, ainda, um novo modelo de educação: Educação Profissional Técnica de Nível Médio. As possibilidades de cursar o Ensino Médio com a Educação Profissional são estabelecidas na LDB vigente no art. 36, da seguinte forma: "I - articulada com o Ensino Médio; II - subsequente, em cursos destinados a quem já tenha concluído o Ensino Médio".

\footnotetext{
${ }^{4}$ Teoria elaborada por Theodore W. Schultz em 1973.
} 
Um ano após a reformulação da LDB, foi estabelecida a estrutura da Educação Profissional, por meio do Decreto no 2. 208/1997, que instituiu regulamentações para a Educação Profissional, propondo as formas: concomitante e subsequente, como articulações entre a formação geral e a formação tecnológica. O referido Decreto determinava, ainda, a separação entre o Ensino Médio e a Educação Profissional, ou seja, sem uma base curricular única. Estava, assim, estabelecida a cisão entre o ensino propedêutico e a Educação Profissional.

A definição do Decreto no 2.208/1997, conforme Jean Santos, (2007), esteve de acordo com o contexto dos anos 1990, ou seja, com a elevação da Educação Básica à condição de prioridade política para a inserção do país no mundo competitivo: globalizado e neoliberal. Assim sendo, a relação estabelecida entre educação e trabalho, no contexto da globalização neoliberal no Brasil, é de que a educação é o meio de capacitar pessoas para fortalecer o mercado de trabalho, de preferência, com uma qualificação aligeirada. Trabalho, nesse caso, recebe também o sentido de empregabilidade ${ }^{5}$, e não de princípio educativo como aquele que contribui para o processo formativo dos sujeitos.

Após o governo FHC, quem assumiu a presidência do Brasil foi Luiz Inácio Lula da Silva, em 2003. Nesse novo governo, o Ensino Médio também sofreu alterações, tais como: a revogação do Decreto no 2.208/1997 e a promulgação do Decreto no 5.154/2004. Durante os debates sobre o futuro do Ensino Médio e da Educação Profissional, houve opiniões distintas quanto à revogação do Decreto no 2.208/1997.

A ideia de revogar o Decreto no 2.208/1997 e substituí-lo por outro ganhou força porque, segundo Frigotto, Ciavatta e Ramos (2005, p. 31), só a revogação do Decreto no 2.208/1997 “não garantiria a implementação da nova concepção de ensino médio e educação profissional e tecnológica". Além disso, para esses autores, o governo do Presidente Lula tinha acordo com os progressistas de revogar o Decreto no 2.208/1997 e que poderia até ter feito isso imediatamente.

O Decreto № 2.208/1997 foi substituído pelo Decreto no 5.154, de 23 de julho de 2004, que regulamenta os art. 36, 39, 40 e 41 da LDB. Esse decreto define as formas de articulação entre a Educação Profissional (integrada, concomitante e subsequente) como apresenta o Parecer no. 39/2004 do Conselho Nacional de Educação (CNE) e da Câmara de Educação Básica (CEB). Sendo assim, havia amparo legal para revogar o Decreto no 2.208/1997. (BRASIL, 1997).

Assim, a "articulação", como propõe o Parecer no 39/2004, "é uma forma de relacionamento entre a Educação Profissional e o Ensino Médio, deixa, assim, de ser adotada a velha fórmula do 'meio a meio' entre as partes da educação geral e de formação especial no Ensino Médio."

Durante o período do governo de Luiz Inácio Lula da Silva foram criados alguns programas para viabilizar a consolidação da reforma e a melhoria da qualidade do Ensino Médio; dentre esses sobressaem: o Programa de Equalização das Oportunidades da Educação Básica (PRODEB) (2005); o Programa de Melhoria do Ensino Médio (PROMED) (2007); e o Programa Brasil

\footnotetext{
${ }^{5}$ De acordo com o Dicionário da Educação Profissional em Saúde (disponível em: http://www.epsjv.fiocruz.br/dicionario/verbetes/emp.html) o termo empregabilidade tem sido compreendido como "a capacidade de o indivíduo manter-se ou reinserir-se no mercado de trabalho, denotando a necessidade de o mesmo agrupar um conjunto de ingredientes que o torne capaz de competir com todos aqueles que disputam e lutam por um emprego."
} 
Profissionalizado (Decreto no 6.302/2007), este último visa fortalecer as redes de ensino que ofertam Educação Profissional e Tecnológica.

\section{CONSIDERAÇÕES FINAIS}

A construção dessa retrospectiva histórica do Ensino Médio e da Educação Profissional no Brasil nos permitiu perceber que há momentos em que ocorrem de forma concomitante e em outros são separados. A base da dicotomia presente na Educação Profissional encontra-se na formação da sociedade brasileira, que destinava o trabalho manual aos escravos e aos pobres. A dualidade entre trabalho manual e intelectual transita pela educação artesanal, industrial e manufatureira e chega ao contexto atual das relações educacionais regidas pelo ideário neoliberal como reflexo da introdução de inovações tecnológicas no setor produtivo.

Essa retrospectiva nos permitiu compreender que esse delineamento histórico foi se constituindo nas tramas do capitalismo globalizado que continua a forjar políticas educacionais não condizentes com as reais necessidades concretas do país, pois no início do século XXI ainda apresenta mazelas e contradições presentes no início da colonização.

Observamos também que ambos foram alvos de muitas reformas, sempre direcionadas para o atendimento às necessidades impostas pelo contexto econômico. A função e a identidade da Educação Profissional fizeram sempre parte dos discursos políticos. A discussão sobre a relação entre a formação profissional no ensino médio não é nova, assim como, as políticas voltadas para a articulação da formação propedêutica com a formação profissional.

Diante do que foi discutido ao longo do texto, defendemos uma educação profissional de forma integrada à Educação Básica. Um tipo de ensino que permita a integração do ensino científico, produzido e acumulado historicamente, com a formação profissional. Para tanto, torna-se inevitável às políticas e reformas educacionais, mas que estas tentem ultrapassar as barreiras que impedem uma educação científica e tecnológica integrada culturalmente ao momento histórico vivenciado no século XXI.

\section{REFERENCIAS}

Boxes, C. (2002). O império marítimo português. São Paulo: Companhia das Letras.

Constituição Federal (1988). Constituição da República Federativa do Brasil. Brasília: Senado Federal.

Decreto ㅇ․ 2.208, de 17 de abril de 1997. (1997). Regulamenta o § 2ㅇ do art. 36 e os artigos 39 a 42 da Lei federal no. 9.394/96. Brasília.

Decreto no 5.154, de 23 de julho de 2004. (2004).. Regulamenta o § 20 do art. 36 e os arts. 39 a 41 da Lei no 9.394, de 20 de dezembro de 1996, que estabelece as diretrizes e bases da educação nacional. Brasília.

Lei de 15 de outubro de 1827. Manda criar escolas de primeiras letras em todas as cidades, vilas e lugares mais populosos do Império. Disponível em: . Acesso em: 10 out. 2014. 
Coelho, M. C. P. (1990). A educação brasileira na nova república. Educação e Filosofia. Uberlândia, n. 4. Recuperado em 18 dezembro, 2014, de http://www.seer.ufu.br/index.php/EducacaoFilosofia/article/view/1244/1126.

Germano, J. W. (2005) Estado militar e educação no Brasil. (4a ed.). São Paulo: Cortez.

Ianni, O. (1998). Globalização e neoliberalismo. São Paulo em Perspectiva. Recuperado em 20 julho de 2014: http://produtos.seade.gov.br/produtos/spp/v12n02/v12n02_03.pdf.

Moura, D. H. (2012). Políticas públicas para a educação profissional técnica de nível médio nos anos 1990 e 2000: limites e possibilidades. In: OLIVEIRA, R. (Org.). Jovens, ensino médio e educação profissional: políticas públicas em debate. Campinas: Papirus.

Queiroz, C. M. et al. (2012, dezembro). Evolução do ensino médio no Brasil. Anais do simpósio internacional o estado e as políticas educacionais no tempo presente, Uberlândia, Brasil.

Santos, B. S. (2002). A globalização e as ciências Sociais. São Paulo: Cortez.

Santos, R. R. (2010) Breve histórico do ensino médio no Brasil. Anais do Seminário cultura e política na primeira república: campanha civilista na Bahia, Ilhéus, Brasil.

Saviani, D. (2008). História das ideias pedagógicas no Brasil. (2a.ed.) Campinas-SP: Autores Associados. 